\section{Investigation of some endogenous antimicrobial peptides in thalassemia}

\author{
Arif Mustafa Efendiyev, \\ Gulnara Ibrahim Azizova, \\ Arzu Ramiz Dadashova
}

Research Laboratory of Biochemistry Department, Azerbaijan Medical University, Baku, Azerbaijan

\begin{abstract}
The aim of this work was a comparative study of the amount of antimicrobial peptides - human neutrophil peptides defensins (HNP), hepcidin, bactericidal/permeability-increasing protein (BPI), and endotoxin in $\beta$-thalassemia. Blood samples of 135 patients with thalassemia were investigated. All patients were divided into 3 groups. The first group included patients with heterozygous form $(n=45)$. The second group consisted of patients with homozygous form before splenectomy $(n=45)$. The third group included patients with homozygous form after splenectomy $(n=45)$. The age of patients varied from 2 to 18 years. Biochemical [unconjugated and conjugated bilirubin, alkaline phosphatase, hemoglobin, ferritin, aspartate transaminase (AST), alanine transaminase (ALT), mean corpuscular volume $(\mathrm{MCV})]$ and immune (IgA, $\operatorname{IgM}, \operatorname{IgG}$, phagocytic activity) parameters were defined. Obtained results suggest that increased levels of endogenous antimicrobial peptides are associated with the development of the infectious process and reflect the dynamics of changes in biochemical parameters and immune status.
\end{abstract}

\section{Introduction}

According to the data from World Health Organization, there are 80-90 million of thalassemia gene carriers in the world. ${ }^{1,2}$ This disease is found mainly in the Mediterranean countries in the Middle East, countries located in the lower part of the Pacific Ocean, and South China with the frequency of the disease gene carriers from $2 \%$ to $25 \%$.

In Azerbaijan every year the number of patients with thalassemia increases. In some regions, this number reaches $15-20 \%$ of heterozygous carriers. Over 200 infants with homozygous $\beta$-thalassemia are born annually in republic. ${ }^{3,4}$

Many studies have been published on biochemical changes in the immune status of patients with $\beta$-thalassemia, but the data on the study of the level of secretion of endogenous antimicrobial peptides in this disease are negligible.

Human body has complex mechanisms of defence against exogenous pathogens and internal risks (malignant growth). Defence strategy is based on the presence of a two-stage protection: non-specific (innate immune system) and specific (adaptive immune system). ${ }^{5}$

Cells of immune system secrete chemokines which direct the inflammatory cells to the lesion, and the danger is eliminated by the united action of phagocytic cells, cytotoxic cells, cytokines and also antimicrobial endogenous peptides.

The aim of this work was a comparative study of the amount of antimicrobial peptides - defensin, hepcidin, protein that increases the permeability of the membranes (BPI) and endotoxin in $\beta$-thalassemia, as well as analysis of the relationship between biochemical indicators, quantity of iron and level of secretion of antimicrobial peptides.

\section{Materials and Methods}

\section{Objects of the study}

This work is based on the results of biochemical and immunological studies of blood samples from patients $(n=135)$ with various forms of thalassemia at the age from 2 to 18 years (60 boys, 75 girls), of those 60 persons aged 1-4 years, 30 persons at the age of 5-7 years, from 8 to 12 years 25 persons, from 13 to 18 years old - 20 persons. The criteria for inclusion of children in the group of survey were the confirmation of the diagnosis of $\beta$-thalassemia, clarification of its form and the patient's age from 2 to 18 years. The diagnosis of $\beta$-thalassemia was confirmed in all children through the study of hemoglobin fractions and also on the basis of criteria for clinical picture of WHO (size of liver and spleen), child's age at the time of the first clinical manifestations, indicator of hemoglobin at the time of diagnosis. In addition, DNA analysis was performed at Thalassemia Center in Baku to confirm the diagnosis of $\beta$-thalassemia as genotypic and define $\mathrm{B}^{0}$, $\mathrm{B}^{+}, \mathrm{B}^{++}$as phenotypic. Splenectomy was performed in all patients at the age from 5 to 12 , with the mean age of splenectomy at 8 years. All patients were divided into 3 groups: the first group included patients with heterozygous form of $\beta$-thalassemia ( $n$ $=45$ persons aged $4-18$ years, including 25 males and 20 females).
Correspondence: Arzu Ramiz Dadashova, Research Laboratory of Biochemistry Department, Azerbaijan Medical University, 98 Mardanov kardashlari, AZ1078, Baku, Azerbaijan.

Tel.: +994.517453274.

E-mail: arzu26@mail.ru

Key words: Defensin; hepcidin; BPI; endotoxin; $\beta$-thalassemia.

Acknowledgements: this work was financially supported by the Science Development Foundation under the President of the Republic of Azerbaijan - Grant № EİF-20101(1)-03/015. The study was based on the study of venous blood of sick children being at the hospital treatment in Scientific Research Institute of Hematology and Blood Transfusion of the Azerbaijan Republic named after B.Eyvazov. We would like to express our sincere gratitude to the head of hemoglobinopathies laboratory, Mrs. Taira Mamedova.

Contributions: AME developed the initial plan of studies, helped in acquisition of necessary material and performed critical revision of the article. GIA developed the final plan of studies, performed all necessary laboratory tests, analysis of obtained data and final conclusions, and prepared the draft of the article. ARD assisted in performing necessary laboratory tests and analysis of obtained data, participated in the installation of necessary equipment, reviewed and edited the draft of the article. All authors contributed to and have approved the final manuscript.

Conflict of interest: the authors declare no conflicts of interest.

Received for publication: 5 August 2018.

Revision received: 22 August 2018.

Accepted for publication: 22 August 2018.

This work is licensed under a Creative Commons Attribution 4.0 License (by-nc 4.0)

(C) Copyright A.M. Efendiyev et al., 2018

Licensee PAGEPress, Italy

Thalassemia Reports 2018; 8:7744

doi:10.4081/thal.2018.7744

The second group consisted of patients with homozygous form before the splenectomy ( $\mathrm{n}=45 ; 27$ of them are girls, and 18 are boys). Patients were at age 14 months through 5 years. The third group consisted of children aged 5-12 years after splenectomy ( $\mathrm{n}=45$, of which 17 are boys and 28 are girls). 20 healthy patients comprised the control group. Written informed consent from the patients was obtained, along with approval from local ethics committee.

\section{Methods of biochemical analysis}

The levels of biochemical parameters 
were determined with semi-automatic analyzer Mindray BA-88A.

Iron was determined with the photometric method using ferene, conjugated bilirubin was determined with colorimetric method with the help of diazo reagent in the acidic environment. Both indicators were measured with the help of reagents from a set of Human Diagnostics Worldwide. Activity of alkaline phosphatase in blood serum was estimated with a standardized method of end point. Activity of ALT and AST was determined with Reitman-Frankel method. Blood hemoglobin levels were measured with a photometric method using potassium ferricyanide at wavelength of $540 \mathrm{~nm} .{ }^{6}$ Statistical analysis was performed using the program STATISTICA 6.0. Data are presented as mean \pm standard error (SE). The Mann-Whitney U-test was used to compare the control group with the groups of patients. $\mathrm{P}<0.05$ was considered statistically significant.

\section{Hematologic and immune indicators}

Determination of erythrocytic parameters [amount of erythrocytes, mean corpuscular volume (MCV) and mean corpuscular hemoglobin in erythrocytes $(\mathrm{MCH})$ ] was performed with the method of Cost.?

Immunoenzymatic indicators $\operatorname{Ig} \mathrm{A}, \operatorname{IgM}$, IgG were determined with Mancini method, phagocytic activity was determined on the basis of phagocytosis ability of leukocytes. ${ }^{8}$

\section{Endogenous antimicrobial peptides}

The concentration of antimicrobial peptides (defensin, endotoxin and BPI) was measured with ELISA method using com- mercial set of Hycult Biotech with the help of microplate reader Mindray MR-96A. The concentration of hepcidin was measured with ELISA method using commercial set of Hepcidin Prohormone Enzyme Immunoassay Kit from IBL International $\mathrm{GmbH}$

\section{Results}

Biochemical and immunological analyses of blood samples of patients in all 3 groups were carried in order to compare the dynamics of changes of antimicrobial peptides with the state of metabolism and the immune status of the studied patients. The results are shown in Table 1.

As seen from Table 1, a notable increase in the level of unconjugated and conjugated bilirubin, ALT is observed in group 3 in patients with $\beta$-thalassemia after splenectomy. Thus, conjugated bilirubin increased by 1.99 times, free bilirubin - by 1.34 times, ALT - by 2.27 times, indicating a decline in the functional state of the liver. $\mathrm{P}<0.05$ compared with the control group was considered statistically significant (MannWhitney U-test). There is a sharp increase in the level of serum iron, ferritin in all 3 groups, thus in group 1 there is 1.9 times increase in iron; in the second group, which included patients with homozygous form of $\beta$-thalassemia before splenectomy, - 2.1 times increase, and in group 3 - 3.25 times increase, indicating the accumulation of iron in the body.

There is a notable reduction in hemo- globin level in the first, second and third groups by $3 \%, 7 \%$ and $30 \%$ respectively. Similar dynamics of changes are observed for the MSV and MCH (see Table 1).

Analysis of the obtained indicators, such as $\operatorname{IgA}$, IgM and $\operatorname{IgG}$, indicates an increase in IgA and IgG (see Table 1). The concentration of IgM does not change significantly. Thus, the average IgG level in the control group was $14.40 \pm 0.21 \mathrm{~g} / \mathrm{L}$. In group 1, there is 1.005 times increase; in the second group - 1.13 times, in the third group - 1.27 times increase compared to control group. In contrast, there is a noticeable decline in phagocytic activity of leukocytes. In Group 1, the average value of this indicator was $32.3 \pm 2.6 \%$, that is by $11.5 \%$ lower than in the control group. In Group 2 it was $23.3 \pm 1.3 \%$, which is by $36 \%$ lower; and in Group 3 with patients with the homozygous form of $\beta$-thalassemia after splenectomy the average value was $16.1 \pm 0.8 \%$, which is by $56 \%$ lower than in the control group. In Group 2, $\mathrm{P}<0.05$ compared with the control group was considered statistically significant (Mann-Whitney U-test). These data indicate the relationship between biochemical and immune parameters in $\beta$-thalassemia. As the object of investigation from endogenous peptides we selected defensin, hepcidin,permeability-increasing protein (BPI) and endotoxin, as they are of great interest in increasing the susceptibility to infections, as well as during infectious complications observed in $\beta$-thalassemia. It is proved that defensins are an integral part of the immune system of many mammalian species. Six types of $\alpha$-defensin and four types of $\beta$-defensin are described in

Table 1. Biochemical and immune parameters in patients with $\beta$-thalassemia.

\begin{tabular}{|c|c|c|c|c|}
\hline Parameter $\quad$ Group of patients & Control group $n=20$ & I group ${ }^{a} n=45$ & II group $\mathrm{n}=45$ & III group ${ }^{\mathrm{n}} \mathrm{n}=45$ \\
\hline Conjugated bilirubin (mkmol/L) & $2.42 \pm 0.15$ & $2.39 \pm 0.17^{*}$ & $2.95 \pm 0.23^{*}$ & $4.8 \pm 0.37^{*}$ \\
\hline Unconjugated bilirubin (mkmol/L) & $12.74 \pm 0.62$ & $13.1 \pm 0.5^{*}$ & $14.5 \pm 0.78^{*}$ & $17.1 \pm 0.92 *$ \\
\hline Alkaline phosphatase (U/L) & $242.7 \pm 3.4$ & $253.1 \pm 4.5$ & $247.8 \pm 1.7$ & $276.2 \pm 4.5$ \\
\hline Hemoglobin HB (g/L) & $108.2 \pm 1.2$ & $105 \pm 2.3$ & $101.2 \pm 2.4$ & $76.1 \pm 0.92$ \\
\hline Serum iron (U/L) & $17.95 \pm 0.38$ & $33.4 \pm 1.2$ & $37.5 \pm 0.13$ & $58.5 \pm 7.1$ \\
\hline Ferritin (ng/ml) & $1625 \pm 114$ & $1750 \pm 98$ & $2104 \pm 117$ & $3865 \pm 305$ \\
\hline $\operatorname{ALT}(\mathrm{U} / \mathrm{L})$ & $0.51 \pm 0.03$ & $0.62 \pm 0.07 * *$ & $1.4 \pm 0.2 * *$ & $1.16 \pm 0.07 * *$ \\
\hline AST (U/L) & $0.42 \pm 0.02$ & $0.47 \pm 0.04^{* *}$ & $0.54 \pm 0.07^{* *}$ & $0.76 \pm 0.004^{* *}$ \\
\hline Mean volume of erythrocytes (MCV) (p/g) & 89 & 76 & 73 & 70 \\
\hline Mean corpuscular hemoglobin in erythrocytes (MCH) (fL) & 28.25 & 26 & 25 & 22 \\
\hline $\operatorname{IgA}(g / L)$ & $1.84 \pm 0.05$ & $1.92 \pm 0.07$ & $2.1 \pm 0.07$ & $2.4 \pm 0.05$ \\
\hline $\operatorname{IgM}(g / L)$ & $2.41 \pm 0.07$ & $2.44 \pm 0.04$ & $2.31 \pm 0.03$ & $2.42 \pm 0.04$ \\
\hline $\operatorname{IgG}(g / L)$ & $14.40 \pm 0.21$ & $14.47 \pm 0.22$ & $16.2 \pm 0.4$ & $18.3 \pm 0.7$ \\
\hline Phagocytic activity, \% & $36.5 \pm 2.5$ & $32.3 \pm 2.6$ & $23.3 \pm 1.3^{*}$ & $16.1 \pm 0.8$ \\
\hline
\end{tabular}

aPatients with heterozygous form of $\beta$-thalassemia; ${ }^{b}$ patients with homozygous form before the splenectomy; ${ }^{\text {p }}$ atients with homozygous form after the splenectomy. ${ }^{*} \mathrm{P}<0.05$, ${ }^{* *} \mathrm{P}<0.001$ compared with the control group (Mann-Whitney U-test). 
humans. $\alpha$-defensins are found in biological fluids of body in neutrophils, monocytes and lymphocytes. They are presented by human neutrophil peptides (HNPs) 1-4 and human defensins (HD) 5 and $6 .{ }^{9}$

Normally, the level of $\alpha$-defensins is below the level required for antimicrobial protection. However, it increases sharply in inflammatory conditions. There are data on a significant, 15-20 times, increase in the concentration of $\alpha$-defensins in inflammatory processes.

The data we obtained on studying the level of antimicrobial peptides and hepcidin are shown in Table 2 and Figure 1.

As seen in the first group, which included patients with heterozygous $\beta$-thalassemia, HNP concentration was $114 \pm 0.9$ $\mathrm{ng} / \mathrm{mL}$, which is $11.8 \%$, i.e. 1.2 times higher than in control. In group 2 with patients before splenectomy it was also observed $514.7 \%$ i.e. 5 times increase in the level of defensin compared to the control, which is much higher than for patients of group 1 . Minimal level of defensin observed in this group is $320 \mathrm{ng} / \mathrm{mL}$, maximal is 1022 $\mathrm{ng} / \mathrm{mL}$, that indicates a strong variation in the amount of defensin before splenectomy, that, apparently, depends on the degree of activation of neutrophils. In group 3, which included patients with homozygous form of $\beta$-thalassemia after splenectomy with larger and more frequent transfusions an increase in the level of defensin amounted for $1551 \%$ or 15.5 times compared to the control. Average observed value was $1582 \pm 142.2 \mathrm{ng} / \mathrm{mL}$, with a minimal value of $1147 \mathrm{ng} / \mathrm{mL}$ in this group and maximum of $2836 \mathrm{ng} / \mathrm{mL} . \mathrm{P}<0.001$ compared with the control group was considered statistically significant (Mann-Whitney U-test).

BPI protein has bactericidal effect, mainly on gram-negative bacteria. It is capable of recognition of lipopolysaccharides (LPS). Recognition of LPS is the most sensitive and specific reaction mechanism of macroorganism in response to invasion of gram-negative bacteria. ${ }^{10}$
In the neonatal period, unlike defensins, BPI is characterized by a low level of production. The content of neutrophils for newborns is 3-4 times lower than neutrophils of adults.

Data on the level of BPI also show positive dynamics of changes. As seen from Table 2, an increase of $466.2 \%$ (4.7 times) is observed in group 1, while there are $2040.5 \%$ (20.4 times) increase in group 2 and $3572.1 \%$ (35.7 times) increase in group 3 , indicating a significant level of changes compared with the control. $\mathrm{P}<0.001$ compared with the control group was considered statistically significant (MannWhitney U-test).

Endotoxin is eliminated from the portal blood system of fixed macrophages, as liver is organ needing endotoxin the most; under its stimulating effect liver produces signal- ing molecules needed for immunity. In case of excess supply (or accumulation) of endotoxin in the general bloodstream, endotoxin aggression is developing and, as a consequence, there firstly occurs the immune hyperactivation with allergic and autoimmune component, and then depletion of immunity with the development of immunosuppressive state. The most common cause of endotoxin aggression, and, consequently diseases, is stress. ${ }^{11}$ Conducted LAL test on the study of the levels of endotoxin also showed an increase in all groups of studied patients. Dynamics of changes in this indicator are similar to changes in defensin. $\mathrm{P}<0.001$ compared with the control group was considered statistically significant (Mann-Whitney Utest). Thus, 5.4 times increase $(545.5 \%)$ is observed in the first heterozygous group, 7

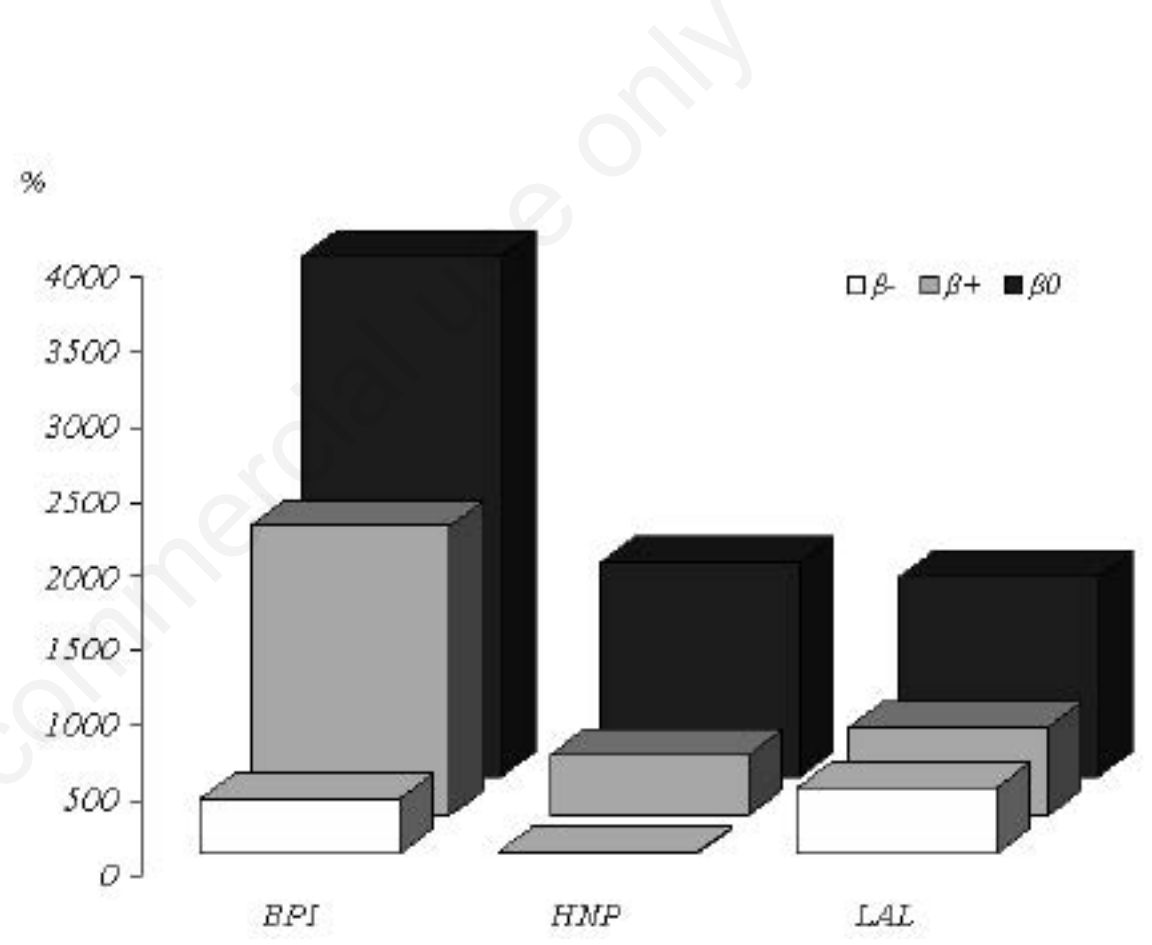

Figure 1. Dynamics of changes in antimicrobial peptides in $\beta$-thalassemia (control = $100 \%)$.

Table 2. Parameters in patients with $\beta$-thalassemia.

\begin{tabular}{|c|c|c|c|c|c|}
\hline Parameter & Group of patients & Control group $n=20$ & I group ${ }^{\mathrm{a}} \mathrm{n}=45$ & II group $^{b} n=45$ & III group ${ }^{c} n=45$ \\
\hline HNP (ng/mL) & & $\begin{array}{c}102 \pm 0.7 \\
(100.4-107.4)\end{array}$ & $\begin{array}{l}114.0 \pm 0.9 * \\
(109-119.3)\end{array}$ & $\begin{array}{c}524.0 \pm 7.07 * \\
(320-1022)\end{array}$ & $\begin{array}{c}1582 \pm 142.2 * \\
(1147-2836)\end{array}$ \\
\hline Hepcidin (ng/mL) & & $\begin{array}{c}87.4 \pm 16.7 \\
(83.2-91.3)\end{array}$ & $\begin{array}{l}81.2 \pm 6.0^{*} \\
(77.1-83.5)\end{array}$ & $\begin{array}{l}23.7 \pm 6.2^{*} \\
(19.5-26.4)\end{array}$ & $\begin{array}{c}62.9 \pm 6.0^{*} \\
(58.9-64.0)\end{array}$ \\
\hline BPI (ng/mL) & & $\begin{array}{c}0.222 \pm 0.019 \\
(0.17-0.35)\end{array}$ & $\begin{array}{c}1.035 \pm 0.020 * \\
(0.83-1.15)\end{array}$ & $\begin{array}{c}4.53 \pm 0.117 * \\
(3.72-5.4)\end{array}$ & $\begin{array}{c}7.93 \pm 1.179 * \\
(4.52-23.21)\end{array}$ \\
\hline LAL (EU) & & $\begin{array}{l}0.033 \pm 0.012 \\
(0.004-0.09)\end{array}$ & $\begin{array}{c}0.18 \pm 0.004^{*} \\
(0.16-0.2)\end{array}$ & $\begin{array}{c}0.23 \pm 0.006^{*} \\
(0.202-0.254)\end{array}$ & $\begin{array}{c}0.476 \pm 0.033^{*} \\
(0.33-0.65)\end{array}$ \\
\hline
\end{tabular}

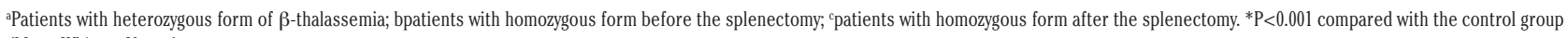
(Mann-Whitney U-test). 
times $(697 \%)$ - in the second group, and 14.4 times $(1442.4 \%)$ - in the third group. The average value of this indicator in the control group was $0.033 \pm 0.012 \mathrm{ng} / \mathrm{mL}$, in the first group $0.18 \pm 0.004 \mathrm{ng} / \mathrm{mL}$, in the second group $0.23 \pm 0.006 \mathrm{ng} / \mathrm{mL}$, and in the third group $0.476 \pm 0.033 \mathrm{ng} / \mathrm{mL}$. Increase in the level of the indicator is probably due to changes of the functional state of liver as metabolism of endotoxin takes place in this organ.

Humoral regulator hepcidin functions between these remotely distant processes of iron metabolism. Obtained data show that the level of hepcidin decreases by 3.7 times compared with the control group in the second group with patients with $\beta$-thalassemia before splenectomy, owing to anemia characteristic for $\beta$-thalassemia. In the third group in the interval between transfusions the hemoglobin level gradually decreases and ineffective erythropoiesis increases. $\mathrm{P}<0.001$ compared with the control group was considered statistically significant (Mann-Whitney U-test).

\section{Discussion}

Studies conducted by a team of scientists have allowed establishing a negative correlation between the activity of natural killer cells (NK) and the amount of transfusions. Preliminary incubation of effector cells with iron chelators led to increased killer activity. ${ }^{12}$ These results indicate that the decrease in activity of NK cells is associated with blood transfusions and excess iron.

A comprehensive study of such morphofunctional properties of neutrophils as phagocytic activity, NBT test (nitroblue tetrazolium test) and also cytochemical figures allowed to establish the change of intracellular biochemical parameters, for example, increased activity of acid and alkaline phosphatase, peroxidase, a decrease in glycogen content, and to identify reduction in absorbent and digesting activities of these cells. ${ }^{13}$ The mechanism of these changes is as follows. Multiple blood transfusions, iron accumulation, frequently observed infectious complications lead to the formation of a large number of circulating immune complexes (CICs) antigen-antibody in the blood plasma of patients with thalassemia. ${ }^{14}$

Phagocytosis and destruction of these complexes are implemented by phagocytes, on the other hand, phagocytes, particularly neutrophils, participate in the removal of hemolysis products from organism.
Consequently, the number of activated neutrophils being at the stage of metabolic explosion increases dramatically in the blood of patients with thalassemia. One of the expected consequences of this process is an increased level of secretion of endogenous antimicrobial peptides by these cells and amplification of non-specific component of the immune system. ${ }^{15}$ It is known that transport function of iron is performed by the main iron-binding protein - transferrin, and iron is deposited as a part of ferritin, mainly in the liver. Besides, iron metabolism involves lactoferrin - iron-containing protein of neutrophils. ${ }^{16}$

Strengthening erythropoietic activity suppresses hepcidin synthesis, resulting in increased adsorption of iron. Tissue hypoxia directly inhibits hepcidin expression in hepatocytes, regardless of iron stores in body. Thus, hypoxia plays a leading role in the regulation of iron metabolism in patients with anemia associated with ineffective erythropoiesis. ${ }^{17,18}$

According to Nemeth et al., suppressive effect of hemolytic anemia on the development of hepcidin is observed even in iron overload of the organism. It can be concluded that the ineffective erythropoiesis is a stronger incentive than an excess of iron, which was supposed to cause the induction of hepcidin. Such interaction of effects explains the cause of hemosiderosis in $\beta$ thalassemia. In such cases, the reduced amount of hepcidin results in iron overload of the organism, and only chelation therapy can prevent this process. In the third group, which includes patients after splenectomy, compared to the second group there is an increase of hepcidin and defensin when frequent transfusions are applied because of the possible development of the inflammatory process. Thus, the secretion of defensin and hepcidin is directly proportional to the intensity of the inflammatory process. However, erythropoiesis is crucial in hepcidin secretion in blood disease. Conclusion: the optimal mode of application of chelation therapy can be selected studying the level of hepcidin, whereas defensin is a marker of inflammatory process. ${ }^{19,20}$

Comparison of the dynamics of changes in BPI with the level of increase in defensin shows a noticeable difference. The explanation for this is, probably, the fact that an increase in the secretion of BPI is the most common characteristic of infectious diseases of respiratory tract. Much more frequently these bacterial diseases of respiratory system such as bronchitis, pneumonia, caused by gram-negative microorganisms, are observed in patients with $\beta$-thalassemia.

\section{Conclusions}

The following conclusions can be summarized:

- An increased secretion of defensin is observed in homozygous form of $\beta$-thalassemia; 5.1 times increase before splenectomy and 15.4 times increase after splenectomy, against the background of lower phagocytic activity of leukocytes and decreased functional state of liver.

- Accumulation of iron is observed in the group of patients with $\beta$-thalassemia with frequent transfusions and, an increase of the endotoxin concentration in blood plasma occurs against this background.

- The optimal mode of application of chelation therapy can be selected taking into account the level of hepcidin.

- Frequent infectious complications lead to increased secretion of BPI.

- Increase in the level of endogenous antimicrobial peptides is the marker of infection process and reflects the dynamics of changes in biochemical parameters and immune status.

\section{References}

1. World Health Organization. Management of haemoglobin disorders: report of joint WHO-TIF Meeting. Geneva: WHO; 2012.

2. Hancer VS, Fisgin T, Buyukdogan M, Bozkurt C. $\beta$-globin mutations in Turkish, Northern Iraqi and Albanian patients with $\beta$-thalassemia major. Thal Rep 2018;8:97-100.

3. Akbarova G. History of the study and solution to the problem of $\beta$-thalassemia in Azerbaijan. J Clin Med Kazakhstan 2013;4:21-8.

4. Asadov C, Mammadova T, Abdulalimov E, et al. The phenotypic manifestations of thalassemic mutations in Azerbaijan. Georgian Med News 2016;261:74-80 [in Russian].

5. Tankayeva KhS, Zhiburt EB. Transfusion of blood in thalassemia in children. Bull DSMA 2018;1:71-7 [in Russian].

6. Kolb VG, Kamishnikov VS. Handbook of clinical chemistry. 2nd ed. Minsk; 1982 [in Russian].

7. Mayanskiy DK, Sherbakov VI, Makarova OP. Comprehensive assessment of the function of phagocytes in inflammatory diseases: methodological recommendations. Novosibirsk; 1985 
[in Russian].

8. Novikov DK, Novikova VI. Evaluation of the immune status. Medicina, Vitebsk; 1996 [(in Russian].

9. Lehrer RI, Lu W. $\alpha$-Defensins in human innate immunity. Immunol Rev 2012;245:84-112.

10. Alexopoulou A, Agiasotelli D, Vasilieva LE, Dourakis SP. Bacterial translocation markers in liver cirrhosis. Ann Gastroenterol 2017;30:486-97.

11. Zampino R, Marrone A, Rinaldi L, et al. Endotoxinemia contributes to steatosis, insulin resistance and atherosclerosis in chronic hepatitis $\mathrm{C}$ : the role of proinflammatory cytokines and oxidative stress. Infection 2018 [Epub ahead of print].

12. Amer J, Fibach E. Chronic oxidative stress reduces the respiratory burst response of neutrophils from beta-thalassaemia patients. $\mathrm{Br} \mathrm{J}$ Haematol 2005;129:435-41.

13. Ezer U, Gülderen F, Culha VK, et al. Immunological status of thalassemia syndrome. J Pediatr Hematol Oncol 2002;19:51-8.

14. Ahluwalia J, Datta U, Marwaha RK, Sehgal S. Immune functions in splenectomized thalassaemic children. Indian J Pediatr 2000;67:871-6.

15. Darzi AA, Kamali S, Khakzad M. Influence of splenectomy on immunoglobulins and complement components in major thalassemia. Caspian J Intern Med 2015;6:30-3.

16. Leecharoenkiat K, Lithanatudom P, Sornjai W, Smith DR. Iron dysregula- tion in beta-thalassemia. Asian Pac J Trop Med 2016;9:1035-43.

17. Kaddah AM, Abdel-Salam A, Farhan MS, Ragab R. Serum hepcidin as a diagnostic marker of severe iron overload in beta-thalassemia major. Indian J Pediatr 2017;84:74550.

18. Jagadishkumar $\mathrm{K}$, Yerraguntla $\mathrm{N}$, Vaddambal MG. Serum hepcidin levels in children with beta thalassemia major. Indian Pediatr 2018;pii:S097475 591600126. [Epub ahead of print].

19. Nemeth E, Valore EV, Territo A, et al Hepsidin, a putative mediator of inflammation, is a type II acutephase protein. Blood 2003;101:2461-63.

20. Ganz T. Hepcidin. Rinsho Ketsueki 2016;57:1913-7. 